\title{
A SENSE OF BELONGING FROM AN EDUCATIONAL CULTURAL PERSPECTIVE - A REVIEW OF RESEARCH
}

\author{
Junko Winch
}

\section{doi: 10.18355/PG.2017.6.2.4}

\begin{abstract}
Students who come to study in the UK from abroad try to adjust to the British educational culture where teaching and learning currently takes place. In the language classroom, teachers also bring and influence their mother tongue language educational culture and their teaching pedagogy to their students. This paper begins how group concepts are viewed by the individualist and collectivist cultures and provides some background knowledge of educational culture. Then, the first part of this article explores what a sense of belonging means and the difference between a sense of belonging and relatedness. It also considers a sense of belonging from individualist and collectivist cultural perspectives. The latter part of the paper aims to answer the question 'Is there any other benefits accompanying a sense of belonging?' The review is based on over 50 studies. Various positive constructs are collected, which becomes evidence that sense of belonging has many benefits. Taking account of educational culture of both language teachers and their students in a classroom, the paper concludes on the recommendations regarding how language teaching practitioners can produce or promote a sense of belonging considering their educational cultural background where they were brought up and the place where they are currently teach.
\end{abstract}

\section{Key words}

Educational culture, relatedness, sense of belonging

\section{Introduction}

A sense of belonging relates to the group concept. Yet, there seems to be a gap between how people view group concept depending on individualist and collectivist cultures.

Individualist is defined as 'the interests of the individual prevail over the interests of the group' (Hofstede et al., 2010: 91). Generally speaking, Anglophone countries are individualist societies although there are some organisations which emphasise the collectivist value (i.e. army) in the individualist societies. 'Group lesson is notoriously difficult to institute because many parents believe that private instruction in which the teacher's undivided attention is focused on only one child is more effective than either group activities or observation of other children's lessons' (Rohlen, LeTendre, 1996: 356) in America.

Group works in individualist countries use informal groups which are usually generated through ad hoc formation and tend to include those of similar academic abilities (White 1987). The characteristics of ad hoc groups are 'loosely, to accommodate a person's needs to maintain his own mobility and to develop individuated skills and career paths...The degree of cohesion 
maintained is just enough to work toward the goals of the group; cohesion is not itself a goal' (White, 1987: 43). So it is a group which consists of people who are individualist.

When forming a group, members go through four stages (Schunk, 2000): forming, storming, norming and performing. The 'forming' stage is the coming together of individuals; in the 'storming' stage, members begin to understand each other; in the 'norming' stage, the team sorts out the roles that each member should play; and in the 'performing' stage, members start the process of solving problems. In order to produce work effectively, members should go through all stages. Ad hoc groups also have to go through these stages every time a group is formed, taking time and effort on the part of each member to establish a fully formed group.

On the other hand, collectivist is defined 'the interest of the group prevails over the interest of individual' (Hofstede et al., 2010: 90). Asian countries are usually collectivist (Dimmock, 2000). Group work is not a novel concept and is consistently embedded and practised in families, schools and work places and is viewed as a positive concept. Benefits of belonging to a group are: 'effective decisions avoid danger, resolving problems, coping with misfortunes and obtain life-sustaining resources' (Baumeister et al., 2002: 817 ) instead of handling everything alone.

Collectivist cultures prefer formal groups which are 'either more or less permanent with defined roles over a long period' (Brumfit, 1985: 72), usually with same members of the group. Unlike ad hoc group formations, members of formal groups do not need to go through all four stages (i.e. forming, storming, norming and performing) (Schunk, 2000) each time they work on groups, but they can start straight to the performing stage skipping three previous stages, which is more effective than ad hoc groups.

Taking note that group concept is perceived differently by individualist and collectivist cultures, this paper begins to define a sense of belonging, which compares on how it differs from 'relatedness'. Then the accompanied benefits are explored in review which has empirical findings. The focus of this review addresses answering the following question 'Is there any other benefits accompanying the sense of belonging?' Due to the focus of this paper, full details of research studies will not always be included (sample, method, age and location etc.).

\section{A sense of belonging, relatedness and its benefits A sense of belonging}

The meaning of a sense of belonging may easily be defined when it is absent. So let us consider the case when people perceive threats to their belonging. They may feel 'isolated, neglected and ignored' (Connell, 1990: 66) or 'feel excluded or rejected ranging from various emotional distress such as loneliness, anxiety, depression (Hunsberger et al., 1994) to feeling like outsiders (Seymour, Hewitt 1997). Experiencing of exclusion may affect psychologically, for example, poorer self-regulation (Baumeister et al., 2005), self-defeating behaviour (Twenge et al., 2002) and poorer cognitive performance (Baumeister et al., 2002). In a study of academic sense of belonging, London et al. (2011) assert that STEM major female students are 
more likely to switch out of their major and low academic performance. According to Glasser (1986), one of the students' five needs includes belonging or love.

Belonging is also defined differently from psychology and sociology. Psychologically, a sense of belonging is 'person's experience of being valued or important to an external referent and experiencing a fit between self and that referent' (Hagerty et al., 1992: 174). This is reiterated as 'recognition and acceptance of a member by other members in a group' (Hagerty et al., 1992: 173). Recognition refers a sense or feeling of valued, respected, needed or important by the member of the group with respect to one's presence and contributions. Acceptance refers 'one' personal belief, the feeling and expectation' (McMillan, Chavis, 1986: 10) that fits in with the group and is accepted and included by the group members and has a place. On the other hand, sociologically, sense of belonging is 'membership in groups' (Hagerty et al., 1992: 174).

Similar to group concept, a sense of belonging is viewed differently from individualist and collectivist societies. Research on specific groups such as students' drug use (Shapes, Solomon, 2003), minority students (Lewis et al., 2016), students with severe disabilities (Williams, Downing, 1998), special needs school students (Pesonen et al., 2016) and mental health (Hagerty, 1992; McLaren, Challis, 2009) are likely to be conducted in individualist countries. That may be why a sense of belonging is emphasized in specific groups in individualist cultures. It is also worth noting that 'contact may be especially important for people who are members of marginalised groups who must cope with negative stereotypes about their group's ability' (Lewis et al., 2016) as it explains why the majority of a sense of belonging research may be focused on minority groups (Zumbrunn et al., 2014: 662) in individualist societies, where a sense of belonging is not embedded in individualist's cultures.

On the other hand, a sense of belonging is experienced by anyone in collectivist countries. A sense of belonging is also consistently encouraged in schools, family and work places. For example, the Japanese government even set out an educational policy emphasizing group concept in 1998. In that policy, the Ministry of Education, Culture, Sports, Science and Technology (MEXT) in Japan identifies desirable group activities as 'a sense of belonging, a consciousness of belonging, feeling of unity, and consciousness of unity among the members' (MEXT 1998). Japanese pupils learn how to behave themselves and how to manage disruptive children in the group by using peer pressure. This is described as follows: 'Orderliness and discipline come to be imposed by the children on one another, rather than by adult authorities' (Stevenson, Stigler, 1994: 70). 'Foreign scholars have often commented on how loose teacher control is in the Japanese classroom, yet things do not fall apart' (Tsuneyoshi, 2001: 77). In individualist educational culture, it may sound strange that pupils have responsibility for reprimanding or managing the disruptive pupil at school as teachers are considered as the only authority to reprimand the disruptive pupils in the class. However, different educational cultures have different methods of running the 
classroom. It is also claimed that cultural cognitive differences exist between Asian and Western learners (Dimmock, Walker, 2005; Watkins, Biggs, 2001).

\section{Relatedness}

Sense of belonging is often referred to relatedness, but what is the difference between relatedness and a sense of belonging? J. P. Connell's (1990) 'relatedness encompasses two aspects of "self" and "others" (parents, peers and teachers)' seems to show the difference between them. If relatedness encompasses the 'self' and 'others', does a sense of belonging also encompass the 'self' and 'others'? If so, there will be no difference between relatedness and a sense of belonging. But if not, that is the difference which will be discussed below.

'The need to experience oneself as worthy and capable of love' (Connell, 1990: 63), or 'being loved' (Hagerty et al., 1992: 173) relates to 'self'. This may be represented in the following statement: 'I think people like me, know and care about me (as a person) and enjoy being with me' (Grolmick, Ryan, 1987). If these needs are met, 'high self-esteem' is experienced (Connell 1990).

'The need to feel securely connected to the social surrounding' (Connell 1990: 63) relates to 'other'. So this 'other' element is a sense of belonging. 'Shared emotional connection' (McMillan, Chavis, 1986: 13) is defined as 'the commitment and belief that members have shared and will share history, common places, time together and similar experiences' (McMillan, Chavis, 1986: 9). Shared emotional connection may be created and grown through sharing the similarity with the group inhabitants which is 'others'. When we try to determine whether one belongs in a setting, we assess how similar to the setting's inhabitants, i.e. 'other' (Lewis et al., 2016). To summarise, sense of belonging is part of relatedness, and a sense of belonging and relatedness are not exactly the same.

From the above explanation, relatedness and a sense of belonging may have occasionally been used interchangeably but they are interchangeable in the meaning. However, 'relatedness' is a bigger concept encompassing two aspects of 'self' and 'other'. Furthermore, the meaning of 'self-esteem' does not seem to be emphasised in a sense of belonging. However, when a sense of belonging is absent, the meaning of 'self-esteem' may be confirmed.

\section{Benefits of a sense of belonging}

Since a sense of belonging is not a novel concept for collectivist countries, other benefits that a sense of belonging may be of more interest for people from collectivist cultures. Benefits are discussed by construct.

\section{Academic motivation}

Motivation tends to be associated with a sense of belonging from various studies. C. Goodenow (1993), alone and also with K. E. Grady (1993), found positive relationships between middle school students' perceptions of belonging and academic motivation. Similarly, D. Solomon et al. (1997) found that elementary school students' sense of community, a construct that included a sense of belonging, was positively associated with their academic motivation. L. H. Anderson and E. M. Anderson's (1999) study also shows 
that a sense of belonging is associated with motivation. L. H. Anderson and E. M. Anderson (1999) found that a sense of belonging was associated with task-goal orientation (focuses on learning, self-improvement and personal effort), which means that a sense of belonging is associated with motivation. Task-goal oriented and ability goal oriented are motivational variables. Taskgoal students are focused on learning, self-improvement and personal effort, whereas ability-goal oriented students are interested in demonstrating their ability to others. V. Battistich et al.'s (1995) study also found that elementary school student's sense of community was associated with motivation. From these findings, 'there is a growing consensus that academic motivation is not purely individual, intrapsychic state; rather it grows out of a complex web of social and personal relationship' (Goodenow, Grady 1993).

\section{Achievement}

Academic achievement consists of two components, self-efficacy 'belief about the extent to which the self is capable of successfully completing tasks' (Lewis et al., 2016: 2) and task utility 'preserving a task or activity to be important, useful and worthwhile' (Lewis et al., 2016: 2). T. M. Freeman et al.'s (2007) study also shows that similar results. Students who felt more belonging were more likely to report high self-efficacy and task utility. S. Zumbrunn et al.'s (2014) study shows that a sense of belonging has been linked to directly to achievement. K. L. Lewis et al. (2016) claim that 'academic success is not solely an individual process driven by differences in abilities and aptitude. Rather, academic success is also a social process influenced by the extent to which students feel a sense of belonging in their academic environment' (Lewis et al., 2016: 4).

\section{Engagement}

Students' engagement with the teacher is predicted as an actual interaction between teacher and students during or after the classroom. These findings seem to imply that a sense of belonging is the teachers' sole responsibility. Teachers may provide students with a sense of belonging by: i) warmth and supportiveness (Solomon et al., 1997); ii) teacher-student relationship to be fair and respect (Murdock et al., 2000); iii) perception of improvement, effort and learning for intrinsic reasons (task or mastery goal) rather than that of grades, outperforming others (ability and performance).

However, C. Furrer and E. Skinner's study (2003) shows that students' perceptions of relatedness to their teacher were associated with engagement in classroom activities. Their study indicates that students' sense of belonging is not the teachers' sole responsibility but classroom activities can also contribute to the students' sense of belonging. As an example of class activity, J. P. McKinney et al. (2006) suggests that a class activity at the beginning of the semester reported students' greater belonging perceptions and encouraged students to get to know one another (Zumbrunn et al., 2014). In addition to class activities, the influence of family and peer has also been noted (Brown, 1990; Coleman, 1961; Steinberg et al., 1992). K. I. Maton et al.'s (1996) research showed ethnic difference of importance between peers and family: friends and peers are thought to be important and influential for 
White students and parent and family support are thought to be important and influential for Black students for social adjustment.

\section{Motivation, engagement and achievement}

From the above studies, the linkage between a sense of belonging and i) motivation, ii) engagement and iii) achievement was demonstrated individually. S. Zumbrunn et al.'s (2014) and J. P. Connell and J. G. Wellborn (1991) conducted study which claims that a sense of belonging is linked to all: i) motivation, ii) engagement and iii) achievement.

S. Zumbrunn et al. (2014) presented two models in their study: one is the common model by J. P. Connell and J. G. Wellborn (1991) and the other one is the elaborated one proposed by S. Zumbrunn et al. (2014). Both models use the similar constructs (i.e. a sense of belonging, motivation (self-efficacy and task value), engagement and achievement) and a sequence of linkages (i.e., a sense of belonging is directly related to engagement and indirectly related to achievement). The only difference between these two is that $\mathrm{S}$. Zumbrunn et al.'s (2014) model specifically stating that a sense of belonging precedes motivation, engagement and achievement. This S. Zumbrunn et al.'s (2014) model shows that a sense of belonging is related to motivation, engagement and achievement.

\section{Motivation, competence, relatedness and autonomy}

The study of any combination of i) motivation, ii) autonomy, iii) competence and iv) relatedness has been investigated in a variety of studies. L. D. Pittman and A. Richmond's (2007) investigated a sense of belonging and iii) competence and showed that students who felt more belonging with their university experienced more competence in their scholastic pursuit. R. M. Ryan et al. (1994) investigated relatedness, ii) autonomy and iii) competence. They found that adolescent who reported being more willing to rely on parents and teachers tended to experience greater competence and autonomy in school. This concludes that 'the higher the perceived quality of relatedness, the greater one's feeling of autonomy and competence' (Ryan, 1995: 419).

\section{Participation}

Classroom involvement and participation is linked to a sense of belonging, as students feel a sense of belonging to a class, participation increases (Watkins, 2005: 52). In fact, active participation is the core element of all research in common (Solomon et al., 1997: 239). Participation may occur in the classroom activity such as face-to-face interaction and contact with the group inhabitants. It may be manifested as: i) individual voluntary contribution to a class, ii) taking-turn or iii) interaction with classmates in a classroom.

Individual contribution may be demonstrated students' answering teacher's questions or expressing their opinions. If students see that their ideas and opinions are welcomed and helpful, this contributes to their continued participation (Solomon et al., 1997: 242). J. D. Finn (1989) identifies four levels of participations, but three levels are discussed here for relevance. The level one participation is 'acquiescing to the need to attend, by prepared and respond to directions or questions initiated by the teacher' (Finn, 1989: 128), 
which is a fundamental level. At the second level of participation, 'students initiate questions and dialogue with the teacher and display enthusiasm by their expenditure of extra time in the classroom before, during and after school or by doing more classwork or homework than is required' (Finn, 1989: 128). The third level of participation is students' autonomy and the opportunity for participation outside of coursework (Finn, 1989).

Interaction with others may be also perceived as class participation. It is claimed that interpersonal interactions with others may have an 'addictive' effect and that when people perceive an environment as caring their need to belong is fulfilled (Baumeister, Leary, 1995). 'Opportunity to interact' students' is one of the factors to influence a sense of belonging (Shapes, Solomon, 2003). That may be why interactive practices and student-centred approach where students are engaging with one another create and grow a sense of belonging than a teacher-centred approach.

\section{Persistence}

Academic persistence refers to determination to succeed. L. R. M. Hausmann et al. (2007) investigated a sense of belonging at university level linked with students' intentions to persist. The students in this study who reported a higher sense of belonging also reported stronger intention to persist. Persistence in the university classroom was shown by students' re-enrolment. C. Good et al.'s (2012) findings also showed that the more the students reported feeling a sense of belonging in mathematics, the more they reported an intention to pursue mathematics in the future, which may enable to conclude that a sense of belonging is more strongly linked to academic persistence. G. M. Walton et al. (2012) conducted experimental manipulation to induce a sense of belonging in some participants and confirmed that participants in the belonging condition persisted longer on an unsolvable mathematics puzzle.

\section{Identification}

The definition of identification among the studies which take sociological perspective is a membership of the group. It is represented in the reciprocal statements 'It is my group' and 'I am part of the group' (McMillan, Chavis, 1986: 10). 'Sense of belonging and identification are often positively correlated with one another' (Lewis et al., 2016: 2). Hence, belonging and identification have occasionally been lumped together in definition and/or measurement (Voelkl, 1996). For example, Finn's (1989) definition of identification 'denotes perception of congruence of the self with an external object (e.g. parents, a social group or institution) in the form of shared values or sense of belonging' (Finn, 1989: 134).

Opposing view exists on whether a sense of belonging encompasses identification or vice versa. J. D. Finn (1989) asserts that 'identification can be seen as an internal state with two components, 'belonging' and 'valuing' (Finn, 1989: 127). This implies that not only a sense of belonging relates to identification but also that identification encompasses a sense of belonging. Contrary to this, L. D. Pittman and A. Richmond (2007) claim the opposite to J. D. Finn (1989)'s: ‘belonging... goes beyond just identification ... but 
includes individual perception of fitting in and belonging with to others' (Pittman, Richmond, 2007: 272), which implies that a sense of belonging encompasses identification. Although different views exist among researchers, there seems to be an agreement that a sense of belonging and identification are related. K. L. Lewis et al. (2016) rightly point out the case where 'it seems possible to be highly identified while simultaneously low in sense of belonging' (Lewis et al., 2016: 2).

To summarise benefits of a sense of belonging, it has many positive constructs such as motivation, engagement, achievement, persistence, participation and identification. In other words, if students answered a sense of belonging to a particular class, students must also have experienced one or more of these constructs.

\section{Recommendations for language teaching practitioners}

As various benefits of academic sense of belonging were confirmed in the above review, this section considers how to produce and promote a sense of belonging by using teachers' individualist or collectivist educational cultures. Language teachers are usually native language speakers who do not necessarily share the same education culture with the institutions where they teach. Teachers who teach European language (French, German and Spanish) are usually considered individualists and those who teach non-European languages (Japanese, Chinese) are considered collectivists. With globalisation, there are cases when non-European language teachers teach in individualist countries or European language teachers teach in collectivist countries. This means that up to four types of educational cultures are involved with language teachers, depending on where they are educated and where they are currently teaching: i) those who have received collectivist education and now teach in collectivist countries (Type 1); ii) those who have received individualist education and now teach in individualist countries (Type 2); iii) those who have received collectivist education and now teach in individualist countries (Type 3) and; iv) those who have received individualist education and now teach in collectivist countries (Type 4).

\section{Teachers who have received collectivist education and now teach in collectivist countries (Type 1)}

Type 1 teachers are those who were brought up in the collectivist culture and continue to teach in the collectivist educational culture. Type 1 teachers have a tacit understanding on how their students can promote a sense of belonging between students and teachers through their past experience through family, school and work. Both teachers and students are familiar with a sense of belonging and there should be no issues arising from cultural differences.

E. R. Hollins (1996) makes a positive statement about teachers and students who share the same educational culture in the teaching and learning environments, "where a common culture is shared among teachers and students, harmony is more likely to naturally exist than in situations where this is not the case' (Hollins, 1996: 123) because 'they are likely to share ways of knowing, understanding, representing, and expressing ideas' (Hollins, 
1996: 140). 'Harmony' between teachers and students means that teachers and students share the same educational culture. If the teacher and students share the same educational cultural background, the situation is less complicated and obvious common sense does not need to be explicitly explained between teacher and students. This is the strength of the teacher and students sharing the same cultural background. However, when it comes to acquiring native-like pronunciation, gestures, behaviors and cognition in language teaching, sharing the same educational culture could be considered as a weakness and students may benefit from learning from native speakers of the language.

\section{Teachers who have received individualist education and now teach in individualist countries (Type 2)}

Type 2 teachers were educated in Anglophone or European countries and are teaching in Anglophone or European countries. Again, as Type 2 teachers and students share the same individualist educational culture, they are also easier to teach their students. Issues arising from cultural differences may not be problematic.

Both Type 2 teachers and students are unfamiliar with the concept of a sense of belonging. However, the majority of current sense of belonging studies is conducted in an individualist country and these are useful for Type 2 teachers. One of the studies to guide how to create an environment to produce a sense of belonging as follows:

'Environments in which students feel supported and cared-about, in which positive interpersonal and intellectual values are stressed, and in which they are given direction but also have reasonable opportunities to participate and be self-directing, fulfil their needs to be autonomous, to be part of a supportive and cohesive group, and to feel increasingly competent (Shapes, Solomon, 2003: 321)'.

When these conditions are met, students will feel a sense of belonging. Furthermore, two teachers' personal qualities to produce a sense of belonging are also suggested: a) warmth and supportiveness (Solomon et al., 1997: 242) and b) kindness and consideration (Solomon et al., 1997: 242).

\section{Teachers who have received collectivist education and now teach in individualist countries (Type 3)}

As Type 3 teachers were brought up experiencing a sense of belonging, they should be able to make students feel a sense of belonging who were not brought up with the concept. Type 3 teachers, who were from collectivist educational culture and now are currently teaching in an individualist country, are likely to unintentionally teach students using collectivist pedagogy. However, their students who are from individualist country may like the teaching pedagogy. For example, Type 3 teachers may use turn-taking unintentionally, and fortunately, turn-taking also works in the individualist educational culture (Winch, 2013).

Type 3 teachers should remember that it is difficult to institute group work in individualist educational culture as group work is a collectivist concept. This may be why group work is only used for marginal people in an individualist 
culture. However, a sense of belonging may be produced through any mutually supportive relationship in a non-competitive environment (Solomon et al., 1997). Mutually supportive relationship may be grown through pair work as it includes 'cooperative learning activities, the active encouragement of students' interaction and expression of ideas (Solomon et al., 1997: 242). Pair work may promote supportive relationships and be replaced to the group work. Actually, pair work is preferred rather than group work in individualist cultures as it allows one-to-one interaction which is preferred by individualist educational cultures and also it allows more opportunity for speaking and expressing ideas than group work (Winch, 2013). Furthermore, pair work also gives the opportunity for students to solve problems together. The stronger student can strengthened his learning by explaining the answer to the weaker student and the weaker students may learn from the stronger student which both students can benefit from pair work.

\section{Teachers who have received individualist education and now teach in collectivist countries (Type 4)}

Similar to Type 3 teachers, Type 4 teachers and students do not share the same educational culture. Type 4 teachers are those who were educated in Anglophone or European countries and now teach in collectivist countries. Type 4 teacher' students are familiar with sense of belonging, but Type 4 teachers are not familiar with the concept.

In this case, Type 4 teachers may be better to have some knowledge on collectivist educational culture and how different students who brought up in collectivist educational culture are from those brought up in individualist one. Firstly, students who were brought up in collectivist educational culture are good listeners rather than speakers and they need some sense of participation as follows:

'They are good listeners, trained to listen to significant others eagerly and carefully, whereas they are not good at expressing their ideas clearly and persuasively. They are not frustrated nor do they become inattentive even when they have little opportunity for verbally expressing their own ideas, as long as they have some sense of participation' (Inagaki et al., 1998: 524).

From the above review, one of the benefits of a sense of belonging was participation. In other word, a sense of belonging can be achieved by students' classroom participation. To promote a sense of belonging in the collectivist students, turn-taking may be used as a language teaching approach as students are familiar with it.

In addition, knowledge that differences in the preferred language teaching approaches exist between American and Asian students is useful. A previous study has shown that different learning preferences exist between American and Asian students. H. Furuhata (2002) tested the participants of students by teaching Japanese using both traditional language teaching and CLT methods. A preference for CLT was confirmed among the American students, whereas Asian students preferred the traditional methods (Furuhata, 2002: 140).

For both Type 3 and Type 4 teachers, E. R. Hollins (1996) warns of teaching and learning environments where students and teachers do not share the same cultural background as follows: ... both teachers and students bring their own 
cultural value, practices and perceptions into the classroom... In classroom setting where a common culture is not shared, careful attention must be given to differences in values, practices and perceptions in order to foster harmony (Hollins, 1996: 123).

\section{Conclusion}

In this paper, it was attempted to summarize key positive constructs accompanying a sense of belonging. It showed adequate evidence of benefits of a sense of belonging and promotes as a useful construct to maximize students' learning. It focused to understand a sense of belonging itself and the relating positive constructs to a sense of belonging and how language teaching practitioners can produce or promote a sense of belonging with combination of educational culture.

Additional work is needed to examine more positive constructs which may be accompanying a sense of belonging. Future studies which investigate if a sense of belonging may become an assessment tool of universities' course evaluation questionnaire may be of interest. Higher educational institutions usually conduct questionnaire to students to evaluate the course and the tutor both quantitatively and qualitatively. These questionnaires include several key constructs such as enjoyment, enthusiasm and interest. However, a sense of belonging seems to be hardly used in the universities' course evaluation questionnaires although it implies that students also experienced other positive constructs such as academic motivation, achievement, engagement, competence, autonomy, participation, persistence and identification.

It is hoped that this paper encourages a sense of belonging among language practitioners beyond marginalized group or minority people at university level in individualist culture.

\section{Bibliographic references}

ANDERSON, L. H. - ANDERSON, E. M. 1999. Social predictors of changes in students' achievement goals orientation. Contemporary Educational Psychology. vol. 24, pp. 21-374.

BANDURA, A. 1986. Social foundations of thought and action. Englewood Cliffs: Prentice-Hall. ISBN: 978-0-13-815614-5.

BATTISTICH, V. - SOLOMON, D. - KIM, D. - WATSON, M. - SCHAPS, E. 1995. Schools as communities, poverty level of student populations, and student's attitudes, motives and performance: A multilevel analysis. American Educational Research Journal. vol. 32, pp. 627-658.

BAUMEISTER, R. F. - DEWALL, N. J. - CIAROCCO, N. J. - TWENGE J. M. 2005. Social exclusion impairs self-regulation. Journal of Personality and Social Psychology. vol. 88, n. 4, pp. 589-604. DOI: 10.1037/00223514.88.4.589.

BAUMEISTER, R. F. - LEARY, M. R. 1995. The need to belong: Desire for interpersonal attachments as a fundamental human motivation. Psychological Bulletin, vol. 117, pp. 497-529.

BAUMEISTER, R. F. - TWENGE J. M. - NUSS, C. K. 2002. Effects of social exclusion on cognitive processes: Anticipated aloneness reduces 
intelligent thought. Journal of Personality and Social Psychology. vol. 83, n. 4, pp. 817-827. DOI: 10.103/0022-3514.83.4.817.

BROWN, B. 1990. Peer groups and peer culture. In S. FELDMAN \& G. ELLIOTT (Eds.). At the threshold: The developing adolescent. Cambridge, MA: Harvard University Press. pp. 171-196.

BRUMFIT, C. J. 1985. Language and Literature Teaching: From Practice to Principle. Oxford, Pergamon Institute of English. ISBN: 978-0135231272. COLEMAN, J. 1961. The adolescent Society. New York: Free Press. ISBN: 978-0313229343.

CONNELL, J. P. 1990. Context, self, and action: A motivational analysis of self-system processes across the life span. In D. CICCHETI \& $\mathrm{M}$. BEEGHLY (Eds.), The self in transition: Infancy to childhood. Chicago: University of Chicago Press, pp. 61-97.

CONNELL, J. P., - WELLBORN, J. G. 1991. Competence, autonomy and relatedness: A motivational analysis of self-system processes. In $\mathrm{M}$. GUNNAR \& L. A. SROUFE (Eds.), Minnesota Symposium on Child Psychology: vol. 23. Self-processes in Development (pp. 43-77). Chicago: University of Chicago Press.

DIMMOCK, C. 2000, Designing the Learning-Centred School - A CrossCultural perspective, London. Routledge Farmer. ISBN: 9780750708500.

DIMMOCK, C. - WALKER, A. 2005, Educational Leadership - Culture and Diversity, London, Sage Publications. ISBN: 9780761971702.

FINN, J. D. 1989. Withdrawing from School. Review of Educational Research. vol. 59, n. 2, pp. 117-142.

FREEMAN, T. M. - ANDERMAN, L. H. - JENSEN, J. M. 2007. Sense of belonging in college freshmen at the classroom and campus levels. The Journal of Experimental Education, vol. 75, n. 3, pp. 203-220. DOI: 10.3200/JEXE.75.3.203-220.

FURRER, C. - SKINNER, E. 2003. Sense of relatedness as a factor in children's academic engagement and performance. Journal of Educational Psychology, vol. 95, pp. 148-161.

FURUHATA, H. 2002, Learning Japanese in America: A Survey of preferred Teaching Methods. Language Culture and Curriculum, vol. 15, n. 2, pp. 134-142.

GLASSER. W. 1986. Control theory in the classroom. New York: Harper \& Row. ISBN: 9780060550158.

GOOD, C. - RATTAN, A. - DWECK, C. S. 2012. Why do women opt out? Sense of belonging and women's representation in mathematics. Journal of Personality and Social Psychology. vol. 102, n. 4, pp. 700-717. DOI: 10.1037/a0026659.

GOODENOW, C. 1993. The psychological sense of school membership among adolescent: Scale development and educational correlates. Psychology in the School. vol. 30. pp. 70-90.

GOODENOW, C. - GRADY, K. E. 1993. The relationship of school belonging and friend's values to academic motivation among urban adolescent students. The Journal of Experimental Education, vol. 62, pp. 6071. 
GROLMICK, W. S. - RYAN, R. M. 1987. Autonomy in children's learning: an experimental and individual difference investigation. Journal of Personality and Social Psychology. vol. 52, n. 5, pp. 890-898.

HAGERTY, B. M. K. - LYNCH-SAUER, J. - PATUSKY, K. L. BOUWSEMA, M. - COLLIER, P. 1992. Sense of belonging: A vital mental health concept. Archives of Psychiatric Nursing, vol. 6, pp. 172-177.

HAUSMANN, L. R. M. - SCHOFIELD, J. W. - WOODS, R. L. 2007. Sense of belonging as a predictor of intention to persist among African American and white first-year college students. Research in Higher Education. vol. 48, pp. 803-839. DOI: $10.1007 / \mathrm{s} 11162-007-9052-9$.

HOFSTEDE, G. - HOFSTEDE, G. J. - MINKOV, M. 2010. Cultures and Organizations - Software of the mind (3rd ed.). New York, NY: McGrawHill Book Company. ISBN: 987-0-07-166418-9.

HOLLINS, E. R. 1996. Culture in School Learning - Revealing the Deep Meaning, Mahwah, NJ, Lawrence Erlbaum Associates Publishers. ISBN: 9780805822656.

HUNSBERGER, B. - PANCER, S. M. - PRATT, M. - ALISAT, S. 1994. The transition to university: Is religion related to adjustment? Research in the Social Scientific Study of Religion, vol. 7, pp. 81-199.

INAGAKI, K. - HATANO, G. - MORITA, E. 1998. Construction of Mathematical Knowledge through Whole-class Discussion. Learning and Instruction. vol. 8, n. 6, pp. 503-526.

LEWIS, K. L. - STOUT J. G. - POLLOCK, S. J. - FINKELSTEIN, N. D.

- ITO, T. A. 2016. Fitting in or opting out: A review of key socialpsychological factors influencing a sense of belonging for women in physics. Physical Review Physics Education Research. vol. 12, n. 2, pp. 110. DOI: 10.1103/PhysRevPhysEducRes.12.020110.

LONDON, B. - ROSENTHAL, S. R. - LOBEL, M. 2011. The influences of perceived identity compatibility and social support on women in nontraditional fields during the college transition. Basic and Applied Social Psychology. vol. 33, pp. 304-321. DOI: 10.1080/01973533.2011.614166. MATON, K. I. - TEI, D. M. - CORNS, K. M. - VIERA-BAKER, C. LAVINE, J. - GOUZE, K. - KEATING, D. P. 1996. Cultural specificity of social support sources, correlates and contexts: Three studies of AfricanAmerican and Caucasian youth. American Journal of Community Psychology, vol. 24, pp. 551-587.

MCKINNEY, J. P. - MCKINNEY, K. G. - FRANIUK, R. - SCHWEITZER, J. 2006. The college classroom as a community: Impact on student attitudes and learning. College Teaching, vol. 54, n. 3, pp. 281-284.

MCLAREN, S. - CHALLIS, C. 2009. Resilience Among Men Farmers: The Protective Roles of Social Support and Sense of Belonging in the Depression-Suicidal Ideation Relation. Death Studies. vol. 33, n. 3, pp. 262-276.

MCMILLAN, D. W. - CHAVIS, D. M. 1986. Sense of community: A definition and theory. Journal of Community Psychology, vol. 14, pp. 6-23. The Curriculum Council, MEXT (1998). 'National Curriculum Standards Reform for Kindergarten, Elementary School, Lower and Upper Secondary School and Schools for the Visually Disabled, the Hearing Impaired and the 
Otherwise Disabled' (Synopsis of the Report). July 29, 1998. Available on line: http://www.geocities.jp/tanbowaii/english/e021.html (Accessed 03/08/17).

MURDOCK, T. B. -ANDERMAN, L. H. - HODGE, S. 2000. Motivational context, student beliefs, and alienation: Stability and change from middle school to high school. Journal of Adolescent Research, vol. 15, pp. 327-351. PESONEN, H. - KONTU, E. - SAARINEN, M. - PIRTTIMAA, R. 2016. Conceptions Associated with Sense of Belonging in Different School Placements for Finnish Pupils with Special Education Needs. European Journal of Special Needs Education. vol. 31, n. 1. pp. 59-75. DOI:10.1080/08856257.2015.1087138.

PITTMAN, L. D. - RICHMOND, A. 2007. Academic and psychological functioning in late adolescence: The importance of school belonging. The Journal experimental Education. vol. 75, n. 4. pp. 270-290. DOI: 10.3200/JEXE.75.4.270-292.

ROHLEN, T. P. - LETENDRE, G. K. 1996. Teaching and Learning in Japan. Cambridge: Cambridge University Press. ISBN: 978-0521495875.

RYAN, R. M. 1995. Psychological Needs and the Facilitation of Integrative Processes. Journal of Personality. Vol. 63, n. 3, pp. 397-427.

RYAN, R. M. - STILLER, J. - LYNCH, J. H. 1994. Representations of relationships to teachers, parents, and friends as predictors of academic motivation and self-esteem. Journal of Early Adolescence. vol. 14, pp. 226249.

SEYMOUR, E. - HEWITT, N. M. 1997. Talking about Leaving: Why Undergraduates Leave the Sciences. Westview Press, Boulder, Co. ISBN: 9780813389264.

SHAPES, E. - SOLOMON, D. 2003. The role of the school's social environment. Educational Leadership. vol. 48, n. 3, pp. 38-42.

SCHUNK, D. H. 2000. Learning Theories - An Educational Perspective. New Jersey, Prentice-Hall Inc. ISBN: 978-0-13-707195-1.

SOLOMON, D. - BATTISTICH, V. - KIM, D. I. - WATSON, M. 1997. Teacher practice associated with students' sense of classroom as a community, Social Psychology of Education. vol. 1, n. 3. pp. 235-267.

STEVENSON, H. W. - STIGLER, J. W. 1994. The learning gap: why our schools are failing and what we can learn from Japanese and Chinese education, New York, Simon \& Schuster. ISBN: 9780671880767. STEINBERG, L. - DORNBUSCH, S. - BROWN, B. 1992. Ethnic differences in adolescent achievement: An ecological perspective. American Psychologist. vol. 47, pp. 723-729.

TSUNEYOSHI, R. 2001. The Japanese Model of Schooling. London, Routledge. ISBN: 978-0815336419.

TWENGE, J.M. - CATANESE, K. R. - BAUMEISTER, R. F. 2002. Social exclusion causes self-defeating behaviour. Journal of Personality and Social Psychology. vol. 83, pp. 606-615.

VOELKL, K. E. 1996. Measuring students' identification with school. Educational and Psychological Measurement. vol. 56, n. 5, pp. 760-770. 
WALTON, G. M. - COHEN, G. L. - CWIR, D. - SPENCER, S. J. 2012. Mere belonging: The power of social connection. Journal of Personality and Social Psychology. vol. 102, n. 3, pp. 513-532. DOI: 10.1037/a0025731.

WATKINS, C. 2005. Classrooms as learning communities: a review of research. London Review of Education, vol. 3, n. 1, pp. 47-64.

WATKINS, D. A. - BIGGS, J. B. 2001. (eds). Teaching the Chinese Learner: Psychological and Pedagogical perspectives. Hong Kong: The University of Hong Kong. ISBN: 978-962-8093-72-4.

WHITE, M. 1987. The Japanese Educational Challenge. The Free Press, London. ISBN: 978-0029338018.

WINCH, J. 2013. An Investigation of the Impact of Japanese Educational Culture: Japanese Language Learning in an International Context. Lap Lambert Academic publishing. Germany. ISBN: 978-3844320176.

WIGFIELD, A. - ECCLES, J. 2002. The development of achievement motivation. San Diego: Academic Press.

WILLIAMS, L. - DOWNING, J. 1998. Membership and belonging in inclusive classrooms: What do middle school students have to say? Journal of the Association For Persons With Severe Handicaps. vol. 23, n. 2, pp. 98-110. ZUMBRUNN, S. - MCKIM, C. - BUHS, E. - HAWLEY, L. R. 2014. Support, belonging, motivation and engagement in the college classroom: mixed method study. Instructional Science. vol. 42, n. 5, pp. 661-668. DOI 10.1007/s11251-014-9310-0.

Dr Junko Winch

Imperial College London

Sherfield Building Level 3

South Kensington Campus

London

SW7 2AZ

United Kingdom

j.winch@imperial.ac.uk 